actinomycetes. Hyphal changes ranged from tho stoppage of further mycelial development to such characteristic morphological effects as stunting, distortion or the formation of hyphal protuberances.

To demonstrate the effects of the actinomycetes on $H$. sativum in soil a buried-slide technique was employed 4 . Microscope slides dipped into a plain agar suspension of $H$. sativum spores were placed in pots of sterilized soil inoculated with one of the actinomycetes. In a similar manner the effect on the fungal hyphæ was determined by incubating the agar slides prior to placing in the soil. It was possible to determine the effects of the actinomycetes on the fungus by periodic removal and microscopical examination of the slides. In all cases the characteristic morphological effects caused by the actinomycete antibiotics in vitro were noted in the soil. Extraction procedures again failed to demonstrate the presence of antibiotics in the soil.

Further proof of the activity of antibiotics in soil was obtained using the antibiotic actinomycin and Actinomyces antibioticus, the organism responsible for its production. In Petri-dish culture both crystalline actinomycin and $A$. antibioticus produce a characteristic swelling, distortion and stunting of the fungal hyphæ. When introduced into sterile soil identical morphological changes are evidenced by $H$. sativum in the presence of either the pure antibiotic or $A$. antibioticus. Extraction of the soil containing the actinomycete yielded no antibiotic, strongly suggesting a localized antagonism due to a relatively high concentration of antibiotic in the immediate vicinity of the actinomycetes.

Soil Microbiology Department,

Rothamsted Experimental Station, Harpenden, Herts ; and

Division of Bacteriology, Science Service,

Department of Agriculture, Ottawa, Canada. Aug. 9.

1 Brian, P. W., Curtis, P. J., and Hemming, H. G., Trans. Brit. Mycol. Soc., 29, $173(1946)$.

${ }^{2}$ Porter, C. L., Amer. J. Bot., 11, 168 (1924).

${ }^{3}$ Elliot, J. A., Amer. J. Bot., 4, 439 (1917).

'Chinn, S. H. F., Can. J. Bot., 31, 718 (1953).

\section{Isolation and Characterization of Biosynthetic Arylsulphates}

Authough most phenols are known to be partially excreted as the corresponding sulphate esters, few arylsulphuric acids have actually been isolated from urine, mainly because of the great solubility of the compounds and their sodium and potassium salts. The $p$-toluidine ${ }^{1}$ and $p$-bromoaniline ${ }^{2}$ salts are less soluble and can be used. to isolate arylsulphates after some preliminary purification of the urine $\theta^{3}$, but are not very satisfactory when the arylsulphates are present in small amounts.

The findings of Egami ${ }^{4}$ that trypaflavin (10-methyl 2 : 8-diaminoacridinium chloride) gave insoluble salts with many different sulphate esters suggested to us that this type of compound might be used to separate arylsulphates from urine. A number of aminoacridines, aminoquinolines and aminopyridines were found to give insoluble salts with arylsulphates, and of the compounds tested 5-aminoacridine was particularly suitable because of its availability and the great insolubility of its readily crystallized arylsulphate salts. The solubilities of these salts in water is of the order of $0.03 \mathrm{gm} . / 100 \mathrm{ml}$. at $4^{\circ} \mathrm{C}$., and they were therefore much less soluble than the $p$-toluidine and $p$-bromoaniline salts mentioned earlier. Unfortunately, the salts do not melt sharply.

A large number of urinary constituents, including some detoxication products, do not give insoluble salts with 5-aminoacridine with the exception of the glucuronides of stilbœstrol and dienœstrol, both of which are known to form relatively insoluble sodium salts ${ }^{5}$. Other compounds which readily gave insoluble 5-aminoacridine salts included dehydro-isoandrosterone sulphate, di-isopropylidene glucose 3-sulphate and the polysaccharide sulphates, carraghenin, laminarin, fucoidin and chondroitin sulphate.

Use has been made of 5 -aminoacridine to isolate the monosulphate of 4-chlorocatechol from the urine of rabbits receiving this compound. Methylation of the free hydroxyl group of the 5-aminoacridine salt and identification of the methylated phenol liberated by subsequent acid hydrolysis established the structure of 4-chlorocatechol monosulphate as 2-hydroxy 4-chlorophenyl sulphate. This confirms the suggestion of Dodgson and Williams ${ }^{6}$ that sulphate conjugation of 4-chlorocatechol occurred on the hydroxyl group para to the substituent chlorine atom.

An arylsulphate isolated as the 5-aminoacridine salt from the urine of rabbits receiving chlorobenzene, and the monosulphate resulting from the treatment of 4-chlorocatechol with half the theoretical amount of chlorosulphonic acid, were shown in the same way to be identical with the arylsulphate obtained after feeding 4-chlorocatechol.

A detailed account of this work will be published elsewhere. Physiology Institute,
Newport Road,

Cardiff. June 16.

* Medical Research Council Student.

${ }_{1}$ Barton, A. D., and Young, L., J. Amer. Chem. Soc., 65, 294 (1943).

${ }^{2}$ Laughland, D. H., and Young, L., J. Amer. Chem. Soc., 66, 657 (1944).

${ }^{3}$ Berenbom, M., and Young, L., Biochem. J., 49, 165 (1951).

${ }^{4}$ Egami, F., J. Chem. Soc. Japan, 60, 853 (1939).

${ }^{5}$ Dodgson, K. S., Garton, A. G., Stubbs, A. L., and Williams, R. T., Biochem. J., 42, 357 (1948)

6 Dodgson, K. S., and Williams, R. T., Biochem. J., 45, 381 (1949).

\section{Effect of Temperature on the Inactivation of Phage labelled with Phosphorus-32}

IN the course of investigations on phage $B M$ labelled with phosphorus-32, we have had occasion to study its inactivation at a temperature of $2-4^{\circ} \mathrm{C}$. and at that of 'dry ice' $\left(-79^{\circ} \mathrm{C}\right.$.). In this way an effect of temperature on the rate of inactivation has been observed, a result which may be of interest in wider investigations recently, made by various authors ${ }^{1}$ on the combined effects of temperature and ionizing agents on viruses and protein molecules.

The investigation has been carried out with the phage $B M$ active on Bacillus megatherium which has been studied for some years in our laboratory ${ }^{2}$. The labelled phage was prepared by infecting cells of $B$. megatherium which had been grown in semi-synthetic medium containing about $3 \mathrm{mc}$. of phosphorus-32 